\title{
University of Adelaide, Australia
}

\author{
Jane Camens and Dominique Wilson
}

\section{Introduction: Creative Writing in the Asia-Pacific Region}

This special issue of TEXT brings together some of the papers, provocations and presentations delivered at a symposium for students and teachers of Creative Writing called 'Writing Across Cultures'. Held in March 2010 at the City University of Hong Kong, the symposium was organised by the university's English Department and the Asia-Pacific Writing Partnership - a regional initiative currently hosted by the Creative Writing Program at the University of Adelaide. This symposium was the first of its kind in the world to focus in the Asia-Pacific region.

Participants from nineteen countries took part in 'Writing Across Cultures'. Most were from countries in Asia and the Pacific, including many Australians, but speakers also came from senior writing programs in North America, the Middle East and the UK. A number of the participants were not attached to any university writing program because there were none in their home country, but all were interested in how they might either establish programs at home or attach themselves to university programs abroad.

While Creative Writing is well established as a discipline in universities in Australia, New Zealand, the Philippines, Hong Kong and Fiji, it has a more tenuous presence as a discipline in universities of most other countries in the region. In some countries, including and especially India, Creative Writing is resisted, partly because it is perceived as a discipline taught in English and, as such, another form of Western cultural imperialism. Several of the papers in this issue address this, including papers by Rukmini Bhaya Nair, Kim Cheng Boey and Brian Castro. They suggest new approaches to teaching Creative Writing in the Asia-Pacific region, including Australia and New Zealand.

'Do not assume the hegemony of English,' Brian Castro advises in his provocation "Teaching Creative Writing in Asia": Four Points and Five Provocations'. He advocates the establishment of translation workshops alongside Creative Writing programs, a proposal that would inevitably expand possibilities for reading across cultures. The benefits for writers of working alongside translators can include further sensitising them to their use of language, showing up weaknesses in clarity of thinking and unintended ambiguities. Literary translators must, after all, be writers able to translate not just the literal meaning of words, but also the more complex 'sense of what is in the foreground and background of any utterance' (a matter Jon Cook addresses in his paper), as well as conveying a sense of the music of the original language. 
In the UK, the British Centre for Literary Translation (BCLT) is embedded within the School of Literature and Creative Writing at the University of East Anglia, facilitating cross-disciplinary collaborations. Some students doing the MA in Creative Writing have been given opportunities through the BCLT to workshop writing-in-progress with students in Spain learning the art of literary translation. This might serve as a model for literary translation/writing workshops in the Asia-Pacific region.

Castro champions a similar direction for writing programs whereby 'crossdisciplinary activities will be the future'. His prescience follows the same path to the future foreseen for Australian Literary Studies by Robert Dixon. On taking up the Chair of Australian Literature at the University of Sydney, Dixon spoke of 'developing intra-disciplinary connections with English and adopting a transnational perspective (that) may offer an opportunity to connect the national literature - and our publishing about it - to world contexts.' (2007: 5-26) This wider perspective on critiquing our literature doesn't negate the need to retain and nurture a grass-roots national literature. Marrying Literary Studies with the creation of literature through Creative Writing as well as Translation programs could open new co-operation and exchange opportunities for writers in universities throughout the region and beyond (we use 'and beyond' from the perspective of our region, not in the way Nair objects to in her paper where 'beyond' was a vague and undifferentiated term for 'the Far East'.)

Kim Cheng Boey proposes that transnational studies be run in correlation to Creative Writing programs. The programs he envisages feature the active presence of writers who have experienced the 'bifocal vision' brought about by cultural displacementwho, in Salman Rushdie's words, 'straddle cultures' or 'fall between two stools' (Rushdie 1992: 15). Boey maintains that Australian and American writers of Asian origin or descent blur notions of what it means to be Australian, American or Asian and that they 'allay fears of cultural imperialism and mediate the passage of Creative Writing into the region'. Boey joins a call by the Indian and Singaporean poets Jeet Thayil and Gwee Li Sui for 'the liberation from postcolonial hang-ups' and 'to move beyond the English/native tongue debate'. He writes:

This is where the Creative Writing program can intervene; it can quicken the new writing and reveal new directions, and at the same time defuse suspicions of any imperialist agenda by fostering interactions with the national and vernacular languages, as well as the different varieties of English such Singapore English or Singlish, Chinglish, Malaysian English and other hybrid varieties that have sprouted all over the region.

A new low-residency MFA in Creative Writing within the English Department at the City University of Hong Kong is stated by its convenor to be the first program in Asia that has a stated focus on writing from the region, most of it by writers who have crossed cultures. The program is taught mostly by 'bifocal' or even polyphonic writers. Exchange programs between that program and at least one Australian university and one in North America are being explored as an outcome of the 'Writing Across Cultures' symposium. 
In 'Thinking Out of the Story Box' Rukmini Bhaya Nair discusses the richness of local languages and oral storytelling traditions. She argues that writing (and writing courses) in South Asia can benefit from attention to traditional modes of storytelling such as that of the kavad or 'story box'. This is a contraption made of light wood that opens to reveal multiple doors, each painted with different brightly coloured scenes. Some panels slide out, some swivel on a stick, some open out like drawers, others fold out. The kavad was carried from village to village in Rajasthan by priests who used it as part of performances to tell the stories of Hindu scripture. As the story progressed, the priest unfolded the doors in a sequence that only he knew. At the conclusion, the box revealed the three-dimensional figure of the god Vishnu giving darshan (direct eye contact with the deity) (Krishnan 2009 ${ }^{1}$ ). A divine metaphor, perhaps, for a short story cycle in which a larger picture comes into focus from many stories. Nair's paper is as cleverly constructed as her kavad.

Jon Cook writes about 'the appeal of language or languages' and the need to listen to that appeal in the light of 'an unprecedented encounter and interaction between different forms and traditions, one that may well reshape our sense of what literature is and its relation to print culture'. His paper deals with a 'special kind of attention to language' needed to write good poetry. He calls us to imagine a poetry workshop dedicated not to writing poems but to reading them, reflecting on the emotions they tap, their 'appeal', and learning the poems 'by heart'. In defence of such a workshop he calls on the work of philosopher Martin Heidegger who wrote of this appeal of language as more than just what someone says but 'the language that speaks in them.' Language has history and is packed with references a speaker may or may not intend. Some references might be intended for only some readers 'in the know' as in Salman Rushdie's Shame in which, as Nair points out, he names a cohort of Pakistani generals with words that mean in Hindi-Urdu 'Garbage', 'Laggard' and 'Useless'. Only HindiUrdu readers get the joke.

When Graham Greene asked Shirley Hazzard about her extraordinary ability to recall innumerable poems, the Australian writer told him that when she was moved by a poem she could remember a line at once. Later she might read it again, say it aloud then remember it always. She said, 'Where there was greatness, the words seemed inevitable, as if memory had been waiting for them' (Hazard 2001).

The importance of acquiring so instinctual a sense of language is the essence of Cook's paper. This then begs two questions: how can Creative Writing be taught in English to students only recently acquainted with the language, and what point is there in this when the students might be acquainted only with the fiddle, drum and pan pipes within the entire orchestral range of linguistic possibilities of the language?

These questions are answered, at least in part, by Dai Fan's fascinating presentation which she illustrated with slides at the symposium in Hong Kong, talking of how she taught Creative Writing to Chinese students within the English department at a university in mainland China. We believe its inclusion in this collection of papers is important as a reminder of the realities of what it might mean to teach English in countries where the chance to tap emotional truths might not be as enthusiastically encouraged as it is elsewhere. 
The paper by Catherine Cole and Marsha Berry explores how historical memory is embedded in a country's fiction, examining the presence of the Vietnam War, or lack of it, in fictions from Vietnamese and Australian writers. The Australian perspective of this paper is unusual in this collection. The paper was not delivered at the 'Writing Across Cultures' conference but was derived from it. We acknowledge here Cole's assistance in the early stages of forming the Asia-Pacific Writing Partnership.

We also gratefully acknowledge Isagini Cruz's contribution to this issue. Current Chair of the Writing Partnership, his particular interest is translingual literature and multilingual literary theory. He is a strong advocate possibilities for refreshing the creative arts through the study and use of more than one language. He writes, 'Teachers of Creative Writing should realize that students with a command, no matter how slight or uneven, of more than one language have a new and relatively unexplored tool on hand for producing works of art.'

We are pleased to have the chance to share these deliberations, knowing that the Australian Association of Writing Programs has recently voted to change its name to the Australasian Association of Writing Programs. We invite its members to become actively engaged with the work of the Asia-Pacific Writing Partnership, which holds its next meeting in December 2011 in conjunction with the Fourteenth Biennial Symposium on Literature and Culture in the Asia-Pacific Region at the University of Western Australia.

\footnotetext{
Note

${ }^{1}$ Krishnan's 'A Portable Shrine (and a piece of clever story-telling)' includes excellent colour photographs of a kavad. See also Macdonald 2000.
}

\section{Works cited}

Dixon, Robert 'Australian Literature-International Contexts', Southerly: A Review of Australian Literature 67, 2007: 5-26, available in part in The Quarterly at http://pen.org.au/static/files/assets/72dfa61b/Q_May07.pdf

Hazzard, Shirley Greene on Capri: A Memoir, Farrar, Straus and Giroux, New York, 2001

Krishnan, Deepa 2009, 'A Portable Shrine (and a piece of clever story-telling)', available at http://delhimagic.blogspot.com/2009/09/have-you-ever-seen-kavad-i-saw-one-in.html

Macdonald, Margaret Read, 'Storytelling Teachers' Workshop', a workshop paper Teaching Through Myth and Metaphor, Asian Art Museum of San Francisco, 2000, available at http://www.asianart.org/pdf/education/MythandMetaphorworkshop.pdf

Rushdie, Salman Imaginary Homelands: Essays and Criticism 1981-1991, Granta, London, 1982

Jane Camens is a PhD candidate in Creative Writing at the University of Adelaide and the founder of the Asia-Pacific Writing Partnership (http://www.apwriters.com).

Dr Dominique Wilson teaches part-time at the University of Adelaide, is Research Assistant for its Creative Writing Program, and is founding Co-Managing Editor of Wet Ink: the magazine of new writing. 
Camens \& Wilson (eds)

TEXT Special issue, Creative Writing in the Asia-Pacific Region, April 2011 